Bài báo khoa học

\title{
Nghiên cứu xây dựng bộ công cụ giám sát hoạt động mạng lưới trạm khí tượng thủy văn
}

\author{
Vũ Ngọc Linh ${ }^{1}$, Nguyễn Minh Hải2 ${ }^{*}$, Nguyễn Văn Lịch ${ }^{2}$, Trịnh Đăng Ba $^{3}$
}

${ }^{1}$ Vụ Quản lý dự báo khí tượng thủy văn; vnlinh@monre.gov.vn

${ }^{2}$ Trung tâm Quan trắc khí tượng thủy văn; hai12bka@gmail.com

${ }^{3}$ Đài Khí tượng Thủy văn khu vực Bắc Trung Bộ; bakttv86@gmail.com

* Tác giả liên hệ: hai12bka@gmail.com; Tel: +84-983591346

Ban Biên tập nhận bài: 05/11/2020; Ngày phản biện xong:17/12/2020; Ngày đăng bài: $25 / 3 / 2021$

Tóm tắt: Hiện nay việc sử dụng các sản phẩm công nghệ thông tin phục vụ công tác quản lý, giám sát ở các ngành, lĩnh vực đang rất phổ biến và hiệu quả. Theo quy định của Luật Khí tượng thủy văn năm 2015, hồ sơ kỹ thuật các trạm là một trong các loại thông tin, dữ liệu khí tượng thủy văn cần được quản lý, giám sát. Nhằm đáp ứng các yêu cầu về quản lý hoạt động mạng lưới trạm quan trắc khí tượng thủy văn theo hướng tự động, hiện đại, nghiên cứu này đã phát triển thành công bộ công cụ phần mềm quản lý hoạt động mạng lưới trạm khí tượng thủy văn, phần mềm có thể cài đặt trên các thiết bị di động thông minh, cho phép người sử dụng dễ dàng truy cập, quản lý, theo dõi trực tuyến tình hình hoạt động của từng trạm quan trắc, giúp nhà quản lý có thể đưa ra các quyết định kịp thời để xử lý các tình huống, sự cố cũng như phục vụ công tác chỉ đạo, điều hành hằng ngày đối với hoạt động của mạng lưới trạm.

Từ khóa: Úng dụng quản lý, giám sát mạng lưới trạm quan trắc khí tượng thủy văn; Hồ sơ kỹ thuật trạm; Quản lý hoạt động trạm quan trắc khí tượng thủy văn.

\section{Mở đầu}

Trong những năm gần đây, mạng lưới trạm quan trắc khí tượng thủy văn được Đảng và Nhà nước quan tâm đầu tư hiện đại hóa, thông qua đầu tư nhiều dự án tăng cường năng lực quan trắc sử dụng nguồn vốn trong nước và vốn viện trợ của nước ngoài. Kết quả, mạng lưới quan trắc khí tượng thủy văn của Việt Nam đang dần được nâng cấp tự động, tiên tiến, hiện đại, mật độ dày hơn và đa dạng các loại mô hình trạm. Sự phát triển mạnh mẽ về số lượng trạm và công nghệ quan trắc cũng đã đặt ra bài toán cho các nhà quản lý mạng lưới trạm, cần phải nắm bắt tình hình hoạt động của các trạm một cách chính xác, nhanh nhất, có hệ thống để đưa ra các quyết định phục vụ công tác chỉ đạo, điều hành, cũng như khắc phục kịp thời các sự cố về thiết bị, đảm bảo hoạt động liên tục, đổn định của mạng lưới trạm [1].

Hiện nay, với sự phát triển mạnh mẽ của thiết bị di động thông minh đã tạo ra môi trường rộng mở cho các nhà thiết kế phần mềm phát triển các ứng dụng phục vụ nhu cầu của con người, đặc biệt sử dụng rất hiệu quả công tác quản lý, giám sát trong nhiều ngành, lĩnh vực.

Nhận thấy tính ưu việt của phầm mềm cài đặt trên thiết bị di động thông minh có thể đáp ứng được các yêu cầu trong công tác quản lý, giám sát hoạt động của mạng lưới trạm quan trắc,nghiên cứu này đã xây dựng thành công bộ công cụ giám sát hoạt động mạng lưới trạm khí tượng thủy văn, có thể cài đặt trên các thiết bị di động như điện thoại thông minh, máy 
tính bảng có kết nối internet, giúp các nhà quản lý có thể giám sát hoạt động mạng lưới trạm một cách trực tuyến, liên tục.

\section{Phương pháp nghiên cứu}

\subsection{Giới thiệu ứng dụng trên thiết bị di động}

Một phần mềm ứng dụng được thiết kế cài đặt chạy trên các thiết bị di động như điện thoại thông minh, máy tính bảng và các thiết bị di động khácđược gọi tắt là "ứng dụng trên thiết bị di động". Các ứng dụng thường có sẵn thông qua các nền tảng phân phối ứng dụng (còn gọi là cửa hàng ứng dụng), bắt đầu xuất hiện vào năm 2008 và thường được điều hành bởi các chủ sở hữu của hệ điều hành di động,như Apple App Store, Google Play, Windows Phone Store, và BlackBerry App World. Một số ứng dụng được cung cấp miễn phí, trong khi một số ứng dụng người dùng phải trả kinh phí [2].

Thuật ngữ "ứng dụng" là một rút ngắn của thuật ngữ "phần mềm ứng dụng", thường được viết là "app" (viết tắt của từ application trong tiếng Anh), từ "app"trở thành từ rất phổ biến trong năm 2010.Ứng dụng di động ban đầu được cung cấp với mục đích thông tin tổng quát và các dịch vụ thông dụng trên mạng toàn cầu, bao gồm email, lịch, danh bạ, và thị trường chứng khoán và thông tin thời tiết. Tuy nhiên, nhu cầu chung của những người sử dụngthiết bị di động và khả năng phát triển của các nhà lập trình đã mở rộng thành các loại khác, chẳng hạn như trò chơi di động, tự động hóa nhà máy, GPS và các dịch vụ dựa trên địa điểm, định vị, các ứng dụng y tế, giám sát, theo rõi sức khỏe, kinh doanh, vận tải,ngân hàng và có thể ứng dụng phục vụ giám sát, quản lý hoạt động trong nhiều ngành, lĩnh vực khác nhau.

\subsection{Phuơng pháp nghiên cứu}

Bộ công cụ giám sát hoạt động mạng lưới trạm quan trắc khí tượng thủy văn được chia làm 02 phần, phần thứ nhất là cơ sở dữ liệu về hồ sơ kỹ thuật trạm, phần thứ hai là phần mềm hiển thị cài đặt trên thiết bị di động ( $\mathrm{app})$, chi tiết phương pháp nghiên cứu như sau:

\subsubsection{Xây dựng hồ sơ kỹ thuật trạm điện tử}

Nghiên cứu đã sử dụng nền tảng MySQL để xây dựng hồ sơ kỹ thuật trạm điện tử cho toàn bộ trạm của mạng lưới trạm quan trắc khí tượng thủy văn quốc gia, MySQL là một hệ thống quản trị cơ sở dữ liệu mã nguồn mở (Relational Database Management System, viết tắt là RDBMS) hoạt động theo mô hình client-server tương thích với nhiều hạ tầng máy tính quan trọng như Linux, macOS, Microsoft Windows, và Ubunt [3,4].

\subsubsection{Xây dựng ứng dụng (app) quản lý hồ sơ hoạt động trạm trên thiết bị thông minh}

Để xây dựng được ứng dụng phục vụ giám sát, quản lý hoạt động của mạng lưới trạm quan trắc khí tượng thủy văn, nhóm nghiên cứu đã đặt ra mục tiêu lựa chọn ngôn ngữ lập trình phù hợp để xây dựng. Úng dụng di động phải hoạt động ổn định trên các thiết bị có hệ điều hành iOS và Android, có chức năng về giám sát, quản lý thông tin về hoạt động, trang thiết bị của các trạm của mạng lưới quan trắc khí tượng thủy văn, chức năng hiển thị trên bản đồ mạng lưới trạm khí tượng thủy văn và thông báo về tình trạng hoạt động của hệ thống trạm, cung cấp cho người sử dụng các báo cáo dữ liệu của các trạm quan trắc một cách chính xác và nhanh chóng. Với ưu điểm tốc độ nhanh trong xử lý dữ liệu trên thiết bị di động thông minh, khả năng hỗ trợ và xử lý tối ưu hóa cao, có thể phát triển trên môi trường Android và iOS, ngữ lập trình React Native do Công ty công nghệ Facebook phát triển đã được nhóm nghiên cứu lựa chọn để xây dựng ứng dụng giám sát hoạt động mạng lưới trạm quan trắc khí tượng thủy văn $[5,6]$. 


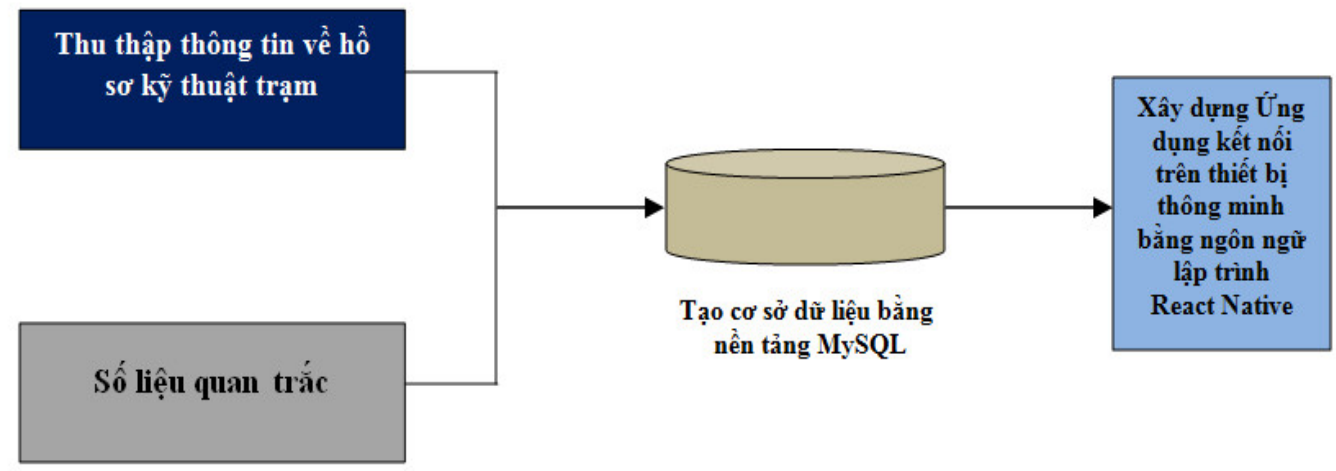

Hình 1. Sơ đồ các bước thực hiện xây dựng bộ công cụ giám sát.

\subsection{Thu thập thông tin, dũ liệu}

Thông tin, dữ liệu phục vụ xây dựng hồ sơ kỹ thuật trạm điện tử gồm: tên trạm, loại trạm, tọa độ, vị trí, nhân sự, hồ sơ thiết bị, quá trình bảo dưỡng, thay thế, kiểm định.Dữ liệu quan trắc (cả trạm thủ công và tự động) sẽ được lưu vào cơ sở dữ liệu theo bảng mẫu có sẵn, được xây dựng phù hợp với tùy theo loại trạm, kiểu trạm, yếu tố quan trắc sẽ truy cập vào từng vùng nhớ dữ liệu theo yêu cầu.

\section{Kết quả nghiên cứu}

\subsection{Các hoạt động kỹ thuật chính để xây dưng bộ công cu}

Trong những năm qua được sự quan tâm của Nhà nước, Chính phủ, hệ thống mạng lưới trạm quan trắc khí tượng thủy văn quốc gia đã được đầu tư thông các dự án trong và ngoài nước (ODA Ý, Nhật, Phần Lan, Hàn Quốc và WB4, WB5...). Hiện tại, mạng lưới trạm quan trắc khí tượng thủy văn quốc gia có khoảng 187 trạm khí tượng, 242 trạm thủy văn và 20 trạm hải văn, 13 trạm khí tượng tự động độc lập, 162 trạm thủy văn tự động độc lập, 14 trạm bức xạ tự động (Hình 2).

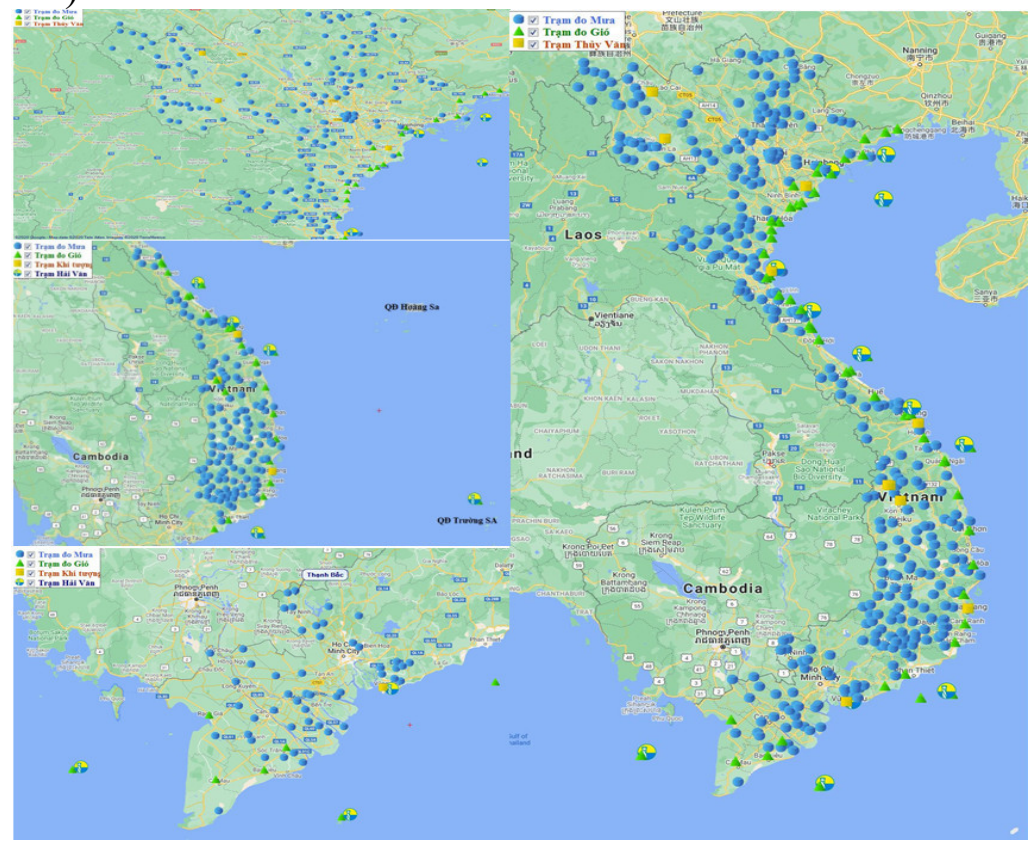

Hình 2. Bản đồ mạng lưới trạm quan trắc khí tượng thủy văn quốc gia.

Để thực hiện được yêu cầu giám sát hoạt động của toàn bộ các trạm quan trắc thuộc mạng lưới quan trắc khí tượng thủy văn quốc gia, nghiên cứu đã xây dựng thành công bộ 
công cụ giám sát hoạt động của tất cả các trạm này thông qua các hoạt động kỹ thuật được nhóm nghiên cứu thực hiện như sau:

\subsubsection{Xây dựng CSDL hồ sơ điện tử kỹ thuật trạm}

a. Xây dựng cơ sở dữ liệu

Hồ sơ kỹ thuật trạm là thành phần cơ bản nhất và quan trọng nhất của phần mềm quản lý hoạt động mạng lưới KTTV. Nhìn vào hồ sơ trạm ta sẽ biết lịch sử hoạt động của trạm, những biến đổi trong thời gian hoạt động của trạm. Hồ sơ kỹ thuật trạm được các quan trắc viên tại trạm hoặc đơn vị quản lý trạm tự động ghi chép thành hồ sơ giấy, việc ghi chép lịch sử hoạt động của trạm chỉ giải quyết được vấn đề lưu trữ, rất bị động trong phục vụ công tác quản lý và ra quyết định. Bằng việc ứng dụng nền tảng MySQL, một cơ sở dữ liệu về hồ sơ điện tử kỹ thuật trạm được tạo, thông tin về mọi sử thay đổi đối với hoạt động trạm quan trắc có thể được cập nhật nhanh chóng thông qua việc nhập, sửa đổi các thông tin từ máy tính có kết nối internet có cài đặt phần mềm trình duyệt (Hình 3 ).

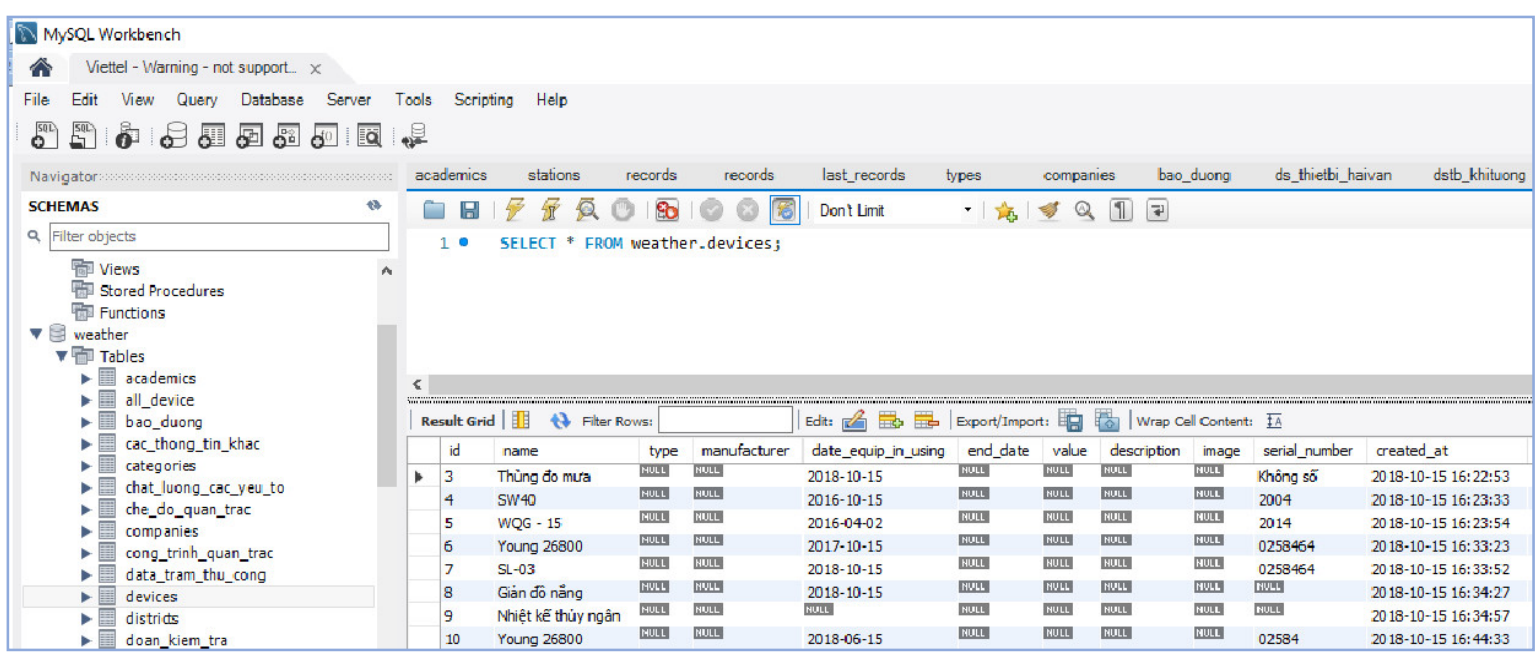

Hình 3. Cơ sở dữ liệu hồ sơ kỹ thuật trạm xây dựng trên nền tảng MySQL.

Do công tác quản lý trạm quan trắc khí tượng thủy văn được phân cấp và chia theo thẩm quyền cho Đài khí tượng thủy văn khu vực. Vì vậy, cơ sở dữ liệu về hồ sơ điện tử kỹ thuật trạm cần được phân quyền truy cập vào hệ thống. Cụ thể được phân thành 04 cấp gồm: cấp trung ương, cấp đài khu vực, cấp tỉnh và cấp trạm (Hình 4).

Tại câpp trung ương được phân cấp cho 03 đối tượng gồm:

- Quản trị hệ thống: thực hiện quản lý tất cả người dùng, trạm quan trắc, danh mục.

- Quản trị trạm: quyền thêm sửa xóa thông tin trạm không có quyền về người dùng, xem, lập báo cáo, cho một loại trạm cụ thể.

- Người dùng, khách: được quyền xem thông tin, tải thông tin, dữ liệu các thống kê, báo cáo (không có quyền thêm, sửa thông tin)

Tại cấp đài khu vực được phân quyền cho 03 đối tượng gồm:

- Quản trị hệ thống: quản lý người dùng, ở đài, trạm.

- Quản trị trạm: quyền thêm sửa xóa thông tin trạm không có quyền về người dùng, xem, lập báo cáo, cho một loại trạm cụ thể, chỉ có quyền truy cập cơ sở dữ liệu của đài mình.

- Người dùng, khách: được quyền xem thông tin, tải thông tin, dữ liệu các thống kê, báo cáo (không có quyền thêm, sửa thông tin).

Tại cấp tỉnh, phân quyền cho 02 đối tượng gồm:

- Quản trị trạm của tỉnh: quản lý người dùng, trạm thuộc tỉnh.

- Người dùng: được quyền xem thông tin trạm, xem tải dữ liệu, thống kê, báo cáo (xem, không có sửa xóa). 
Tại cấp trạm: phân quyền cho 01 đối tượng là trưởng trạm, quản lý thông tin của trạm mình quản lý.

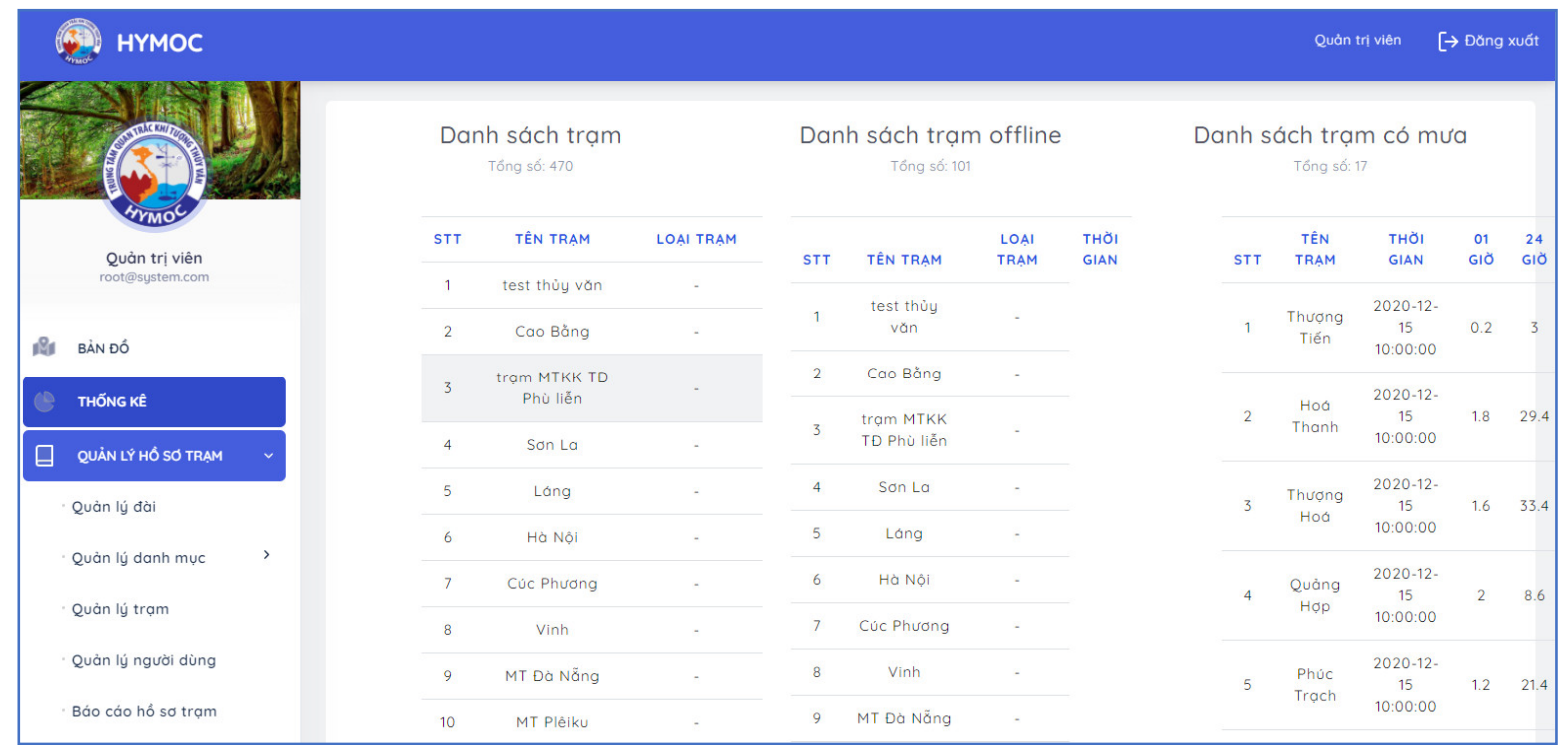

Hình 4. Giao diện truy cập thông tin dành cho quản trị hệ thống.

b. Xây dựng chức năng thống kê

Ngoài phân quyền truy cập cho hệ thống, cơ sở dữ liệu về hồ sơ kỹ thuật trạm còn được bổ sung chức năng thống kê, để hỗ trợ cho chức năng này, các bảng biểu được thiết kế sẵn cho từng loại dữ liệu. Ngoài ra, chức năng thống kê còn thiết kế để tự động lựa chọn các trị số đặc trưng của dữ liệu quan trắc từ các trạm khí tượng thủy văn (Hình 5).

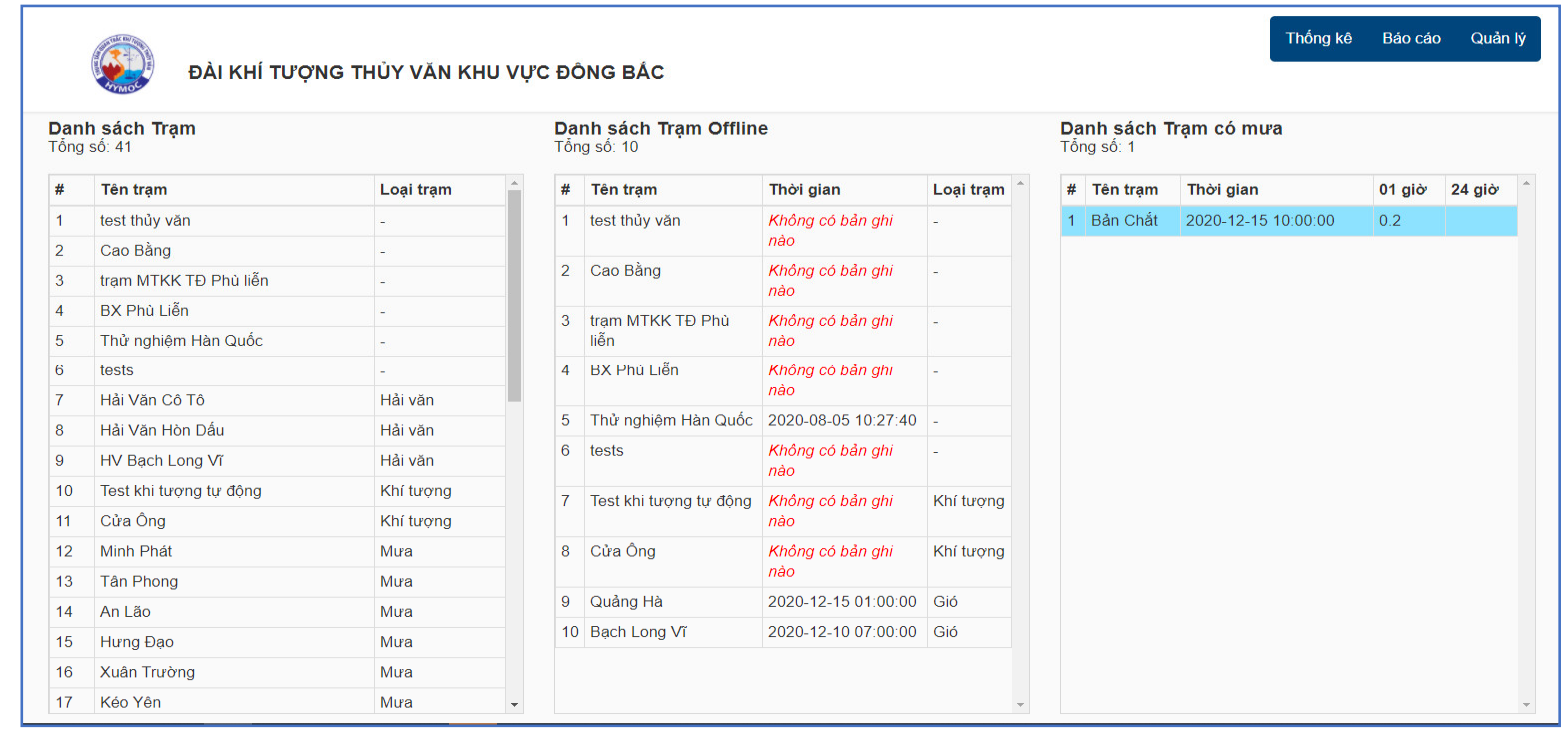

Hình 5. Giao diện chức năng thống kê trong cơ sở dữ liệu.

\subsubsection{Xây dựng ứng dụng (app) quản lý hoạt động mạng lưới trạm trên thiết bị di động}

Để phục vụ hiệu quả công tác quản lý hoạt động mạng lưới trạm quan trắc khí tượng thủy văn, nghiên cứu đã đặt ra các yêu cầu để thiết kế ứng dụng, hướng tới mục đích tiện lợi, dễ sử dụng, dễ quản lý. Các tiêu chí đặt ra đối với ứng dụng khi xây dựng phải đáp ứng một số yêu cầuvề hiển thị như: vị trí của trạm trên bản đồ,trạng thái hoạt động của trạm, mức cảnh báo của trạm, loại trạm theo icon, kiểu trạm, công cụ tìm kiếm trạm trên bản đồ, thống kê hoạt động của trạm. 
Thông qua sử dụng ngôn ngữ lập trình React Native, nghiên cứu đã xây dựng thành công một ứng dụng (app) quản lý hoạt động của các trạm khí tượng thủy văn, cài đặt trên thiết bị thông minh cầm tay như điện thoại di động, máy tính bảng, với đầy đủ các tính năng:

a. Hiển thị theo dạng bản đồ

Với mục đích đưa cho người dùng có góc nhìn trực quan nhất, ứng dụng đã thiết kế hiển thị mạng lưới trạm trênbản đồ Google map, giúp người dùng có thể đánh giá được mật độ trạm trên toàn quốc, phân biệt được các loại trạm (theo các ion khác nhau), nhận biết được trạm đang hoạt động, trạm đang bị trục trặc hoặc ngừng hoạt động thông qua hiển thị màu sắc của icon (Hình 6).
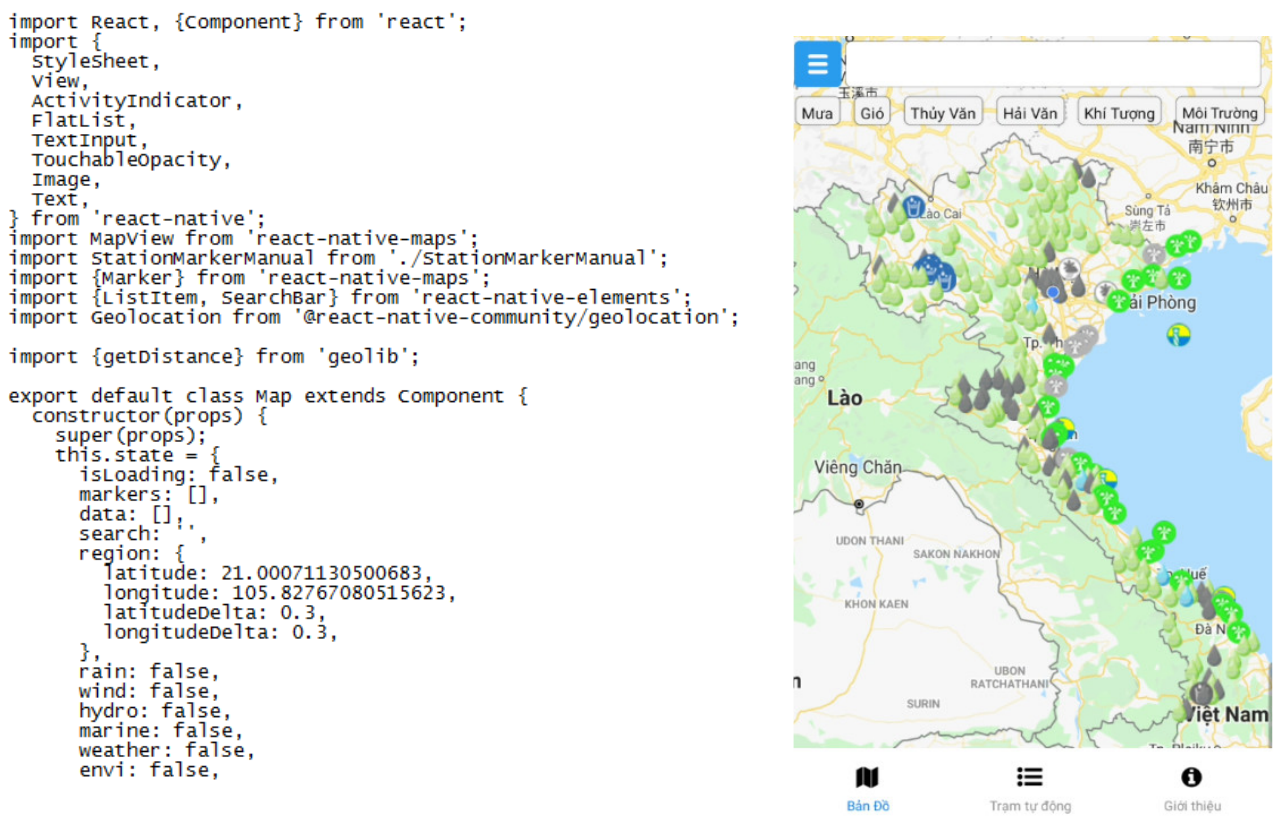

Hình 6. Giao diện ứng dụng giám sát hoạt động mạng lưới trạm cài đặt trên thiết bị di động thông minh.

Các trạm quan trắc hiển thị trên bản đồ, người dùng có thể chạm vào biểu tượng trạm, phần mềm sẽ hiển thị đầy đủ các thông tin của trạm như: thông tin trong hồ sơ kỹ thuật trạm, tình trạng thiết bị, tình trạng hoạt động, thống kê các đặc trưng, hiển thị biến trình của số liệu quan trắc theo thời gian, tình trạng vi phạm hành lang kỹ thuật...vv. Ngoài ra, người sử dụng có thể theo dõi hoạt động của trạm theo đài khu vực, do danh sách trạm đã được sắp xếp quản lý theo đài khu vực (Hình 5).

b. Chức năng tìm kiếm

Được thiết kế nên nền bản đồ của Google map, người dùng có thể sử dụng chức năng tìm kiếm trên thanh công cụ (search bar) để tìm kiếm trạm theo tên, chức năng tìm kiếm có hỗ trợ gợi ý tên nếu người dùng không nhớ đầy đủ tên trạm.

c. Chức năng thống kê

Chức năng này được thiết kế để hiện thị các đặc trưng thống kê của các trạm quan trắc. Các thông tin cơ bản của từng trạm bao gồm mực nước, Obs và PIN. Các bản tin được gửi theo thời gian 10 phút, với mực nước hiện tại, Obs lượng mưa và dung lượng pin còn lại. Dựa trên các thông tin đó có thể đánh giá mức độ thay đổi, đưa ra nhận định các trường hợp có thể xảy ra (Hình 7). 

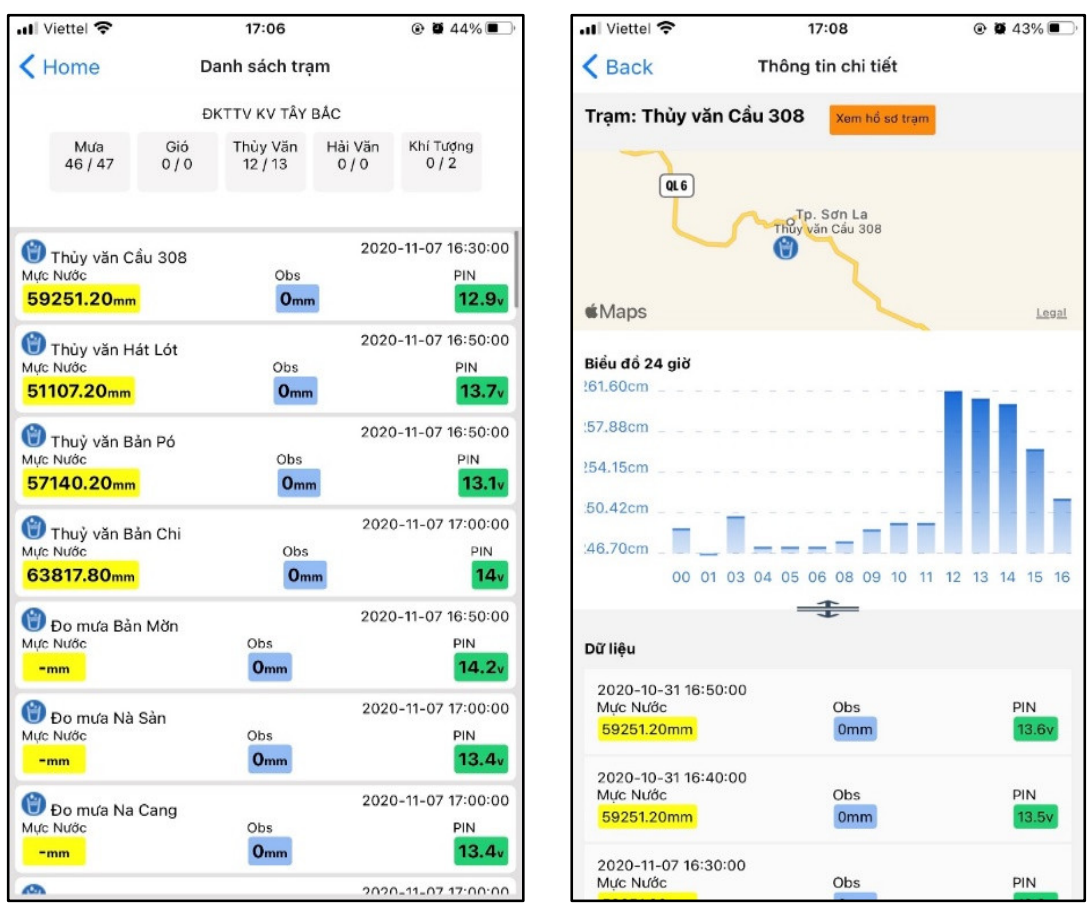

Hình 7. Giao diện hiển thị các đặc trưng thống kê của các trạm.

\subsection{Tính hiệu quả thư nghiệm ưng dụng giám sát hoạt động mạng luới trạm}

Úng dụng hoạt động tốt trên cả hai hệ điều hành iOS và Android, các tính năng hoạt động ổn định, không xảy ra hiện tượng thoát hoặc treo ứng dụng trong khi sử dụng. Không gây ra xung đột với các phần mềm khác khi hoạt động. Ứng dụng cung cấp các công cụ cần thiết cho việc quản lý hệ thống mạng lưới quan trắc khí tượng thủy văn.

Đã cung cấp cho người sử dụng những công cụ cần thiết cho việc khai thác nhanh số liệu, cung cấp lập các báo cáo theo yêu cầu. Cho phép người quản trị viên giám sát hệ thống một cách trực quan, có thể báo cáotình trạng hoạt động mạng lưới trạm một cách nhanh chóng và chính xác, giúp nâng cao năng lực quản lý hệ thống mạng lưới trạm.

\section{Kết luận}

Ứng dụng công nghệ phần mềm trong quản lý các ngành, lĩnh vực kinh tế-xã hội đã và đang được thực hiện rất hiệu quả, đặc biệt các lĩnh vực có đối tượng liên quan đến không gian, thời gian như khí tượng thủy văn. Với những tính năng ưu việt của việc sử dụng ngôn ngữ lập trình, nhóm nghiên cứu đã xây dựng thành công bộ ứng dụng (app) quản lý, giám sát hoạt động của các trạm khí tượng thủy văn, thông qua ứng dụng này, cán bộ quản lý được trang bị thiết bị như điện thoại di động, máy tính bảng có kết nối internet có thể nắm bắt toàn bộ thông tin, tình trạng hoạt động của tất cả các trạm quan trắc khí tượng thủy văn trên toàn quốc mọi lúc, mọi nơi.

Úng dụng quản lý, giám sát hoạt động mạng lưới trạm quan trắc khí tượng thủy văn đã hoàn thiện và chạy thử nghiệm thành công, cho phép người dùng truy vấn và hiện thị thông tin, hoạt động của trạm theo thời gian thực, trợ giúp người dùng có cơ sở để đưa ra các quyết định nhanh chóng, kịp thời trong hoạt động chỉ đạo, điều hành.

Đóng góp của tác giả: Xây dựng ý tưởng nghiên cứu: V.N.L., T.Đ.B.; Lựa chọn phương pháp nghiên cứu, xây dựng bộ công cụ: N.M.H., N.V.L.; Viết bản thảo bài báo: T.Đ.B.; Chỉnh sửa bài báo: V.N.L. 
Lời cam đoan: Tập thể tác giả cam đoan bài báo này là công trình nghiên cứu của tập thể tác giả, chưa được công bố ở đâu, không được sao chép từ những nghiên cứu trước đây; không có sự tranh chấp lợi ích trong nhóm tác giả.

\title{
Tài liệu tham khảo
}

1. Khánh, D.V. Nghiên cứu xây dựng giả pháp tự động hóa quản lý hoạt động nghiệp vụ trạm khí tượng thủy văn và truyền tin theo thời gian thực từ các trạm khí tượng thủyvăn truyền thống. Đề tài nghiên cứu khoa học cấp bộ, 2018.

2. Ableson, W.F.; Sen, R.; Chris King, C.; Ortiz, C.E. Android in action. Manning Publications, 2012, pp. 664.

3. Smirth, B.O. Introduction to SQL for Data Scientists. College of Business Administration University of Nebraska at Omaha. Avaliable online: http://downloads.bensresearch.com/SQL.pdf

4. Douglas, K.; Douglas, S. PostgreSQL: a comprehensive guide to building, programming, and administering PostgresSQL databases, 2005.

5. https://developer.apple.com/library/ios/documentation/IDEs/Conceptual/iOS_Simu lator Guide/Testingonthe.OSSimulator/TestingontheiOSSimulator.html

6. https://developer.android.com/reference/android/app/Application

\section{Study on building mobile software for operation and monitoring hydro-meteorological station network}

\author{
Vu Ngoc Linh ${ }^{1}$, Nguyen Minh $\mathrm{Hai}^{2 *}$, Nguyen Van Lich ${ }^{2}$, Trinh Dang $\mathrm{Ba}^{3}$ \\ ${ }^{1}$ Department of Hydro-meteorological Forecasting Management: vnlinh@monre.gov.vn \\ ${ }^{2}$ Center for Hydro-meteorological Observation; hai12bka@gmail.com \\ ${ }^{3}$ North Central Eegional Hydro-meteorological Center; bakttv86@gmail.com
}

\begin{abstract}
Currently, the use of information technology products for management and supervision in all sectors and fields is very popular and effective. According to the Law of Meteorology and Hydrology 2015, technical records of stations are one of the types of hydro-meteorological information and data that need to be managed and monitored. In order to meet the requirements of automatic and modern management of hydro-meteorological monitoring stations, this research has successfully developed a set of software tools for managing the network of meteorological stations. Hydrology, software can be installed on smart mobile devices, allowing users to easily access, manage, and monitor online activities of each monitoring station, helping managers to make timely decisions to situations and incidents as well as serve the daily direction and administration for the operation of the station network.
\end{abstract}

Keywords: Application of management and monitoring of hydro-meteorological monitoring station network; Technical records of stations; Management of hydro-meteorological monitoring stations. 